\title{
Clinicopathological Analysis of Ovarian Tumours at Birendra Military Hospital
}

\author{
Khatri $\mathbf{R}^{1}$
}

'Department of Gynaecology, Shree Birendra Hospital

\begin{abstract}
Introduction: Ovarian cancer is the second most common genital tract malignancy accounting for $25 \%$ gynaecological malignancy. This study was conducted to determine the incidence, epidemiological factors and clinical presentation of different types of ovarian tumours their correlation with histopathology.

Methods: This is a descriptive study conducted in Birendra Military Hospital over a period of 2 years. The case records of all the patients with ovarian tumur was analyzed.

Results: Of the total of 135 adnexal masses cases 100 (74.07\%) were found to be histologically proven ovarian tumour out of which 35 were non neoplastic conditions. Benign tumours comprised of $68(68 \%)$ and $32(32 \%)$ were malignant and borderline.Mature cystic teratoma $28(75 \%)$ was the commonest benign tumour, whereas serous cystadenocarcinoma $13(64.3 \%)$ were commonest malignancy. Age varying from $2.5 \mathrm{yrs}$. To 70 yrs. Smallest tumour size was $2.5 \mathrm{~cm}$. largest was $40 \mathrm{~cm}$. Commonest symptom was abdominal discomfort and most common sign was abdominal lump. Malignancy usually presented with ascites especially epithelial ovarian tumours. Germ cell tumour was observed in younger age group in earlier stage.

Conclusion: The commonest ovarian tumor was epithelial followed by germcell. Mature cystic teratoma was the most common benign tumour and malignant was serous cyst adenocarcinoma. Epithelial ovarian tumour prevalent in perimenopausal and postmenopausal age group whereas germ cell in earlier age.
\end{abstract}

Key words: Ovarian tumours, Histopathology, Epithelial, Germ cell, Benign, Borderline, Malignant, Serous, Mature cystic teratoma

\section{Introduction}

Ovarian cancer is the second most common genital tract malignancy accounting for $25 \%$ gynaecological malignancy. It accounts for $6-7.5 \%$ of all cancer and is the fifth most common form of malignancy in women in the United States or sixth in world being highest in the Scandinavian countries $(14.9 / 100,000)$ and lowest in Japan $(27 / 100,00)^{1}$.

It is one of the leading cause of death from gynaecolgical malignancies, approximately in $50 \%$ of deaths that occur at all age.Very few detailed study has been conducted so far in Nepal regarding ovarian tumour. So, this study titled A Clinicopathological Analysis Of Ovarian Tumour At Birendra Military Hospital was undertaken to study the incidence and clinicopathologic correlation of ovarian tumour in the Army families.

\section{Methods}

This is a descriptive study of two years duration conducted in Birendra Military Hospital in the Department of Obstetric and Gynaecology from September 2008 to September 2010 on all the cases of ovarian tumour admitted during the period.

\section{Address for Correspondence:}

Name: Dr. Ratna Khatri

E-mail: khatri.shirish@yahoo.com

Ph. №.: 9841328007 


\section{Results}

Of the total of 1200 gynaecological admissions 135 women were found to have adnexal masses out of which $100(74 \%)$ cases were histologically proven to be ovarian tumour.

Among 100 women 32(32\%) cases were malignant and borderline. 35 women had non tumorous condition.

Benign ovarian tumours were $68 \%$, borderline $3 \%$ and malignant ovarian tumour were $29 \%$. The commonest ovarian tumour was of epithelial origin $56 \%$ followed by germ cell tumour $37 \%$. Mature cystic teratoma was the commonest benign ovarian tumour28 $(75 \%)$ of the total germ cell tumour. 3 cases were discovered of residual ovarian tumour with malignant changes in mature cystic teratoma $6-10 y r s$. after vaginal hysterectomy. Serous cystadenocarcinoma was found in 13 cases $(64.3 \%)$ of epithelial ovarian tumour which was the most common malignant tumour seen usually in age group $40-50 y r s$.of age. Benign epithelial ovarian tumour were 36 (64.2\%) in the age ranging from $18-69 y$ rs. One of the interesting and rare cases to report is 56 yrs. old postmenopausal lady presented with abdominal discomfort. Clinically found to have abdominal lump of size $25 \mathrm{~cm}$. and patient was unaware of it. She never gave history of acute abdominal pain ever before. Ultrasound revealed ovarian mass. Staging laparotomy was done, very strange to see huge ovarian mass was twisted thrice at its pedicle. Left ovary was solid in nature. Histopathological examination showed Serouscystadenoma of left ovary and Brenner tumour of rt. Ovary. It is very rare to see the association of Brenner with Serouscystadenoma.

Mucinous cystadenocarcinoma were 4 cases

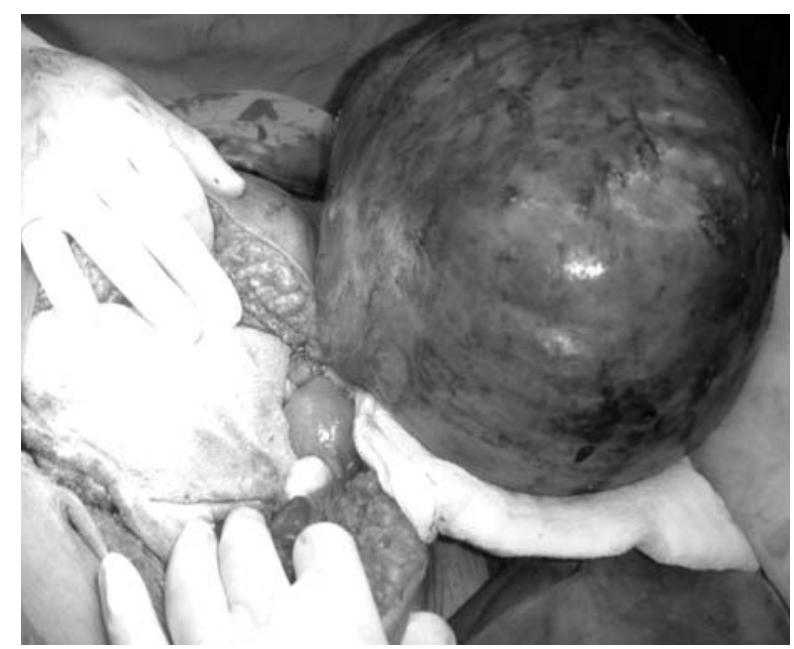

Huge twisted ovarian cyst
(7.14\%) was prevalent in age group 40-69 yrs Sex cord stromal tumours were $3(10.34 \%)$ seen in postmenopausal women presented with increased per vaginal bleeding. Majority of the benign germ cell tumour were mature cystic teratoma $28(75 \%)$ seen in age varying from $2.5 y$ rs.-48yrs. Among which $40 \%$ presented with acute abdominal pain due to torsion and rest with chronic abdominal pain due to long standing twist followed by gangrenous changes. One of the case had mixed echotexture of dermoid with serouscystadenoma in multilobulated ovarian mass in 14yrs. old girl. Miscellaneous tumour Krukenberg was observed in perimenopausal age.There is a wide variation in the size of ovarian tumour. Serous cystadenoma measured $30 \mathrm{~cm}$. weighing $5 \mathrm{~kg}$. with $4 \mathrm{lts}$. of serous fluid within it. A huge dermoid of $35 \mathrm{~cm}$. weighed $6 \mathrm{~kg}$. seen in perimenopausal lady of 46 years.

In young girl of 17 years dysgerminoma of $40 \mathrm{~cm}$. size weighed $5 \mathrm{~kg}$.is also one of the rare occurrence. Majority of benign ovarian tumour had unilateral distribution except 5 cases which were bilateral, while, more than half of malignant tumours were bilateral. Abdominal discomfort and retrosternal burning was the most common symptom noted. Malignancy presented with additional symptom like weight loss and anorexia. Malignancy of epithelial origin mostly presented with ascites who received neo-adjuvant chemotherapy followed by staging laparotomy and chemotherapy postoperatively. Tumour associated with pregnancy was found in primigravida $20 \mathrm{yrs}$. of age discovered at $14 \mathrm{wks}$. of gestational age during antenatal examination who underwent surgery at16 wks. of gestation. This tumour was nothing else but dermoid which is usually seen in association with pregnancy and most likely to twist.

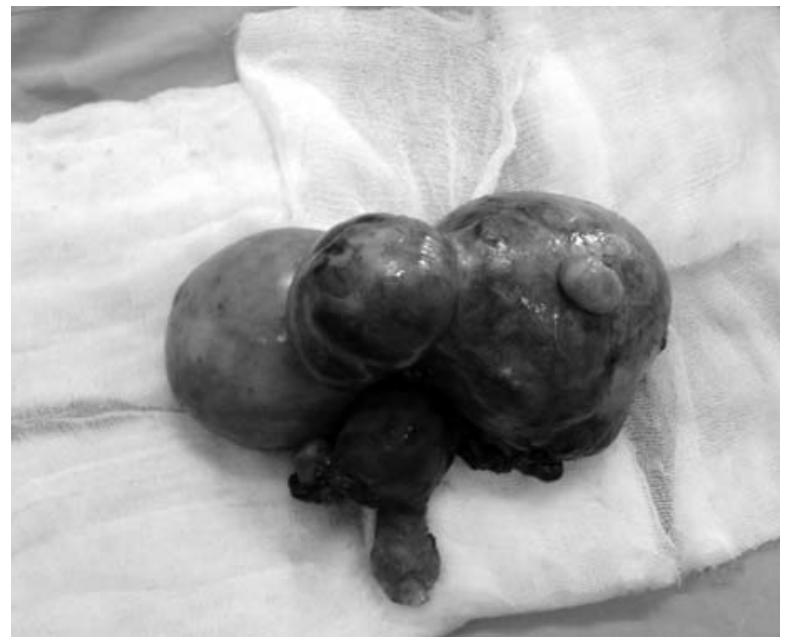

Huge multilobulated dermoid cyst 
Table 1: Types of ovarian tumour according to age (years)

\begin{tabular}{|l|l|c|c|c|c|c|c|c|c|}
\hline Ovarian tumour & Types & $\mathbf{2 - 1 0}$ & $\mathbf{1 0 - 1 9}$ & $\mathbf{2 0 - 2 9}$ & $\mathbf{3 0 - 3 9}$ & $\mathbf{4 0 - 4 9}$ & $\mathbf{5 0 - 5 9}$ & $\mathbf{6 0 - 6 9}$ & $\mathbf{7 0}$ \\
\hline $\begin{array}{l}\text { Epithelial } \\
(\mathrm{N}=56)\end{array}$ & $\begin{array}{l}\text { Benign -36 } \\
\text { Borderline-2 } \\
\text { Malignant-18 }\end{array}$ & & 4 & 5 & 14 & 8 & 4 & 2 & \\
\hline $\begin{array}{l}\text { Sex cord } \\
(\mathrm{N}=4)\end{array}$ & Benign & & & 2 & 8 & 4 & 4 & \\
\hline $\begin{array}{l}\text { Germ cell } \\
(\mathrm{N}=37)\end{array}$ & Benignant & & & & & & & & \\
\hline Metastatic & Malignant-8 & 1 & 2 & 10 & 8 & 4 & 3 & 1 & \\
Krukenberg & & & & & & 1 & & & \\
$\mathrm{~N}=1$ & & & & & & & & & \\
\hline $\begin{array}{l}\text { Mixed } \\
\mathrm{N}=2\end{array}$ & & & & & & 1 & 1 & & \\
\hline
\end{tabular}

Table 2: Ovarian tumour associated with gynaecological and other pathology

\begin{tabular}{|l|l|}
\hline Clinical condition & Types of ovarian tumour \\
\hline Fibroid uterus & $\begin{array}{l}\text { Fibroma } \\
\text { Serous cystadnoma }\end{array}$ \\
\hline Residual ovarian syndrome & Mature cystic teratoma with malignant transformation \\
\hline UV prolapse & Serous cystadenoma \\
\hline Endometriotic cyst (chocolate cyst) & Serous cystadenoma \\
\hline Pregnancy & Maturecystic teratoma \\
\hline Hydronephrosis & Serous cystadenocarcinoma \\
\hline Deep vein thrombosis & Krukenberg's tumour \\
\hline
\end{tabular}

\section{Discussion}

According to the world cancer report, cervical cancer is the most common cancer of the female reproductive tract. It is said that about 470000 new cases are diagnosed each year. The incidence is higher in developing countries and has been declining in the last three or four decades in most developed countries, predominantly due to effective cervical screening programs. We conclude from this study that ovarian tumours are much more frequent gynaecological malignancies than cervical cancer ${ }^{2,3}$.

Ovarian tumours are a group of neoplasm affecting the ovary and have a diverse spectrum of features according to the particular tumour entity. They include benign,low malignant potential or borderline and malignant subtypes.

Ovarian cancer is a disease produced by the rapid growth and division of cells within one or both ovaries reproductive glands in which the ova, or eggs, and the female sex hormones made. The ovaries contain cells that under normal circumstances reproduce to maintain tissue health. When growth control is lost and cells divide too much and too fast a cellular mass or tumour is formed. If the tumour is confined to a few cell layers, for example, invade surrounding tissues or organs, it is considered benign 4 .

If the tumour spreads to surrounding tissues organs, it is considered malignant, or cancerous. When cancerous cells break away from the original tumour travel through the blood or lymphatic vessels and grow within other parts of the body, the process is known as metastasis ${ }^{4}$.

Infact, there are 30 known histopathologic, or diseased tissues types.

Experts group ovarian cancers within three major categories, according to the type of cells from which they were formed.

- Epithelial cancers, which are the most common ovarian cancers, arise from cells lining or covering the ovaries.

- $\quad$ Germ cell cancers start from germ cells (cells that are destined to form eggs) within the ovaries. 
- Sex cord, stromal cell cancers, benign in the cells that hold the ovaries together and produce female hormones.

Also the tumour like conditions are not ovarian tumours, thus presented by this study, 100 being histologically proven ovarian tumours $35(26 \%)$ were non neoplastic cystic lesios like endometriotic cyst, follicular cyst and corpus luteal cyst which has been excluded from the study.

Nearly $2 \%$ of women born in the United States are at risk of developing ovarian cancer in their lifetime. Ovarian cancer most frequently appears in women who are older than 60 (about $50 \%$ of patients are over age 65), although it may occur in younger women who have a family history of the disease.Ovarian cancer is responsible for $5 \%$ of all cancer deaths among women.

\section{Causes and risk factor}

There is a link between the total number of ovulations during a woman's life.

There are four principal factors ${ }^{5}$

- Never having been pregnant. The more times times a woman has become pregnant the lower her risk is. Contrary to this, our study showed mostly females were multiparous.

- None of the patients in the study had ever taken oral contraceptives. Taking the pill for 15 yrs. Halves the risk of ovarian cancer a study by the Collabarative group and Epidemeliological studies of ovarian cancer found. The use of oral contraceptives has a protective effect against the development of ovarian cancer 6 .

- Many women of the study group had started their periods at an early age have a higher risk of ovarian cancer. Most of the women included in the study had menopause.Scientists at the centre for Disease Control and Prevention (CDC) found that survival among women with ovarian cancer is also influenced by age of menarche and total number of lifetime ovulatory cycles.

\section{Ovarian epithelial tumours traced to fallopian tubes}

Similar to one of the case in this study the source of disease in many cases of the most aggressive form of ovarian cancer, serous adenocarcinoma, may not be the ovary at all, but rather the fimbria of the fallopian tube, according to the findings presented at the 2008 American Association for Cancer Research Annual Meeting ${ }^{7}$.

\section{Risk of ovarian carcinoma from hormone therapy}

Women who have taken hormone therapy are at a higher risk of ovarian cancer than who have not, according to Danish study published 2009 issue of Journal of the American Medical Association.

None of the patient included in this study had a family history of ovarian, breast or colonic cancer. Studies have reported that the risk is higher in women who have one first degree relative and one second degree relative with ovarian cancer. The risk is even higher in women who have two or three first degree relatives with ovarian cancer. Hereditary ovarian cancer makes up approximately 5- $10 \%$ of all cases of ovarian cancer. Three hereditary pattern have been identified

- Ovarian Cancer alone

- Ovarian Cancer and breast cancer

- Ovarian and colon

\section{Foods high in acrylamide}

A study in the Netherlands found a link between acrylmide a carcinogenic compound found in cooked, and especially burned, carbohydrate rich foods and increased risk of endometrial and ovarian cancer in postmenopausal women.

Similarly to this study the study group mostly belong to the remote villages occupation mainly agriculture. So, people in Nepal are fond of burned food items, staple diet is rice which is carbohydrate rich food. One of the patient in the study had endometriotic cyst along with serous cystadenoma. Women who develop endometriosis have an approximately $30 \%$ higher risk of developing ovarian cancer compared to other women.

\section{Obesity and overweight}

Several studies have also shown that obese cancer patients are more likely to have faster advancing ones compared to cancer patient of normal weight.

Women who had their tubal ligation done are estimated to have $67 \%$ lower risk of ovarian cancer. Very few cases had tubal ligation done in this study. 
A hysterectomy is said to reduce the risk by about one-third. Out of so many cases of hysterectomy done two cases had develop malignant transformation in mature cystic teratoma after 6-10 yrs. of vaginal hysterectomy ${ }^{8}$.

Ovarian tumour can occur at all age ranging from $2.5 \mathrm{yrs}$. To $70 \mathrm{yrs}$. In this study Sex cord stromal tumour were found in postmenopausal age group in contrary to the epithelial tumours and malignant germ cell tumour occurred at almost all age group varying from menarchal, reproductive and menopausal age. Squamous cell cancer arising in mature cystic teratoma was observed in more than $45 \mathrm{yrs}$. of age. Krukenberg tumour seen in age under $50 \mathrm{yrs}$. of age.For all age groups, benign tumours were more common than malignant ones. Most ovarian tumours were seen between 21-40 years whereas most malignant tumours were seen above 40 years $^{9}$.

Incidental findings being a case of Krukenberg during follow up for gastric ulcer. In of the case during antenatal check up gestational height was more than gestational age. Ultrasonography was done revealed dermoid. While staging laparotomy was done for unilateral ovarian tumour other side of the ovary was found solid in nature later histologically proven to be fibroma.

\section{Unilateral or bilateral distribution}

Benign ovarian tumours were mostly unilateral and malignant were bilateral.

\section{Consistency}

Of the cystic tumours $94 \%$ were benign. Mature cystic teratoma $75 \%$ was the commonest Serous and mucinous cystadenocarcinoma formed little exception. Half of the solid tumours were benign Brenner and fibroma three each. Mixed consistency was also malignant and the only solid tumour was Krukenberg tumour.

\section{Ovarian tumour associated with pregnancy}

The incidence of ovarian tumours during pregnancy is $1 \%$ which is comparable to other series. Ovarian tumours in pregnancy is usually diagnosed in the first and second trimester of pregnancy ${ }^{10}$.

Acute abdomen was the presentation due to torsion and rupture. Ovarian malignancy is the second commonest gynaecological cancer detected during pregnancy.

\section{Conclusion}

The commonest ovarian tumour was epithelial followed by germ cell. All types of ovarian cancer except germ cell tumours increased in incidence until the seventh and eight decades of life, after which the rates plateaued. Rates of epithelial tumours were greatest in single woman, whereas nonepithelial tumour occurrence showed no coorelation with marital status ${ }^{8}$. Mature cystic teratoma were predominant in benign group and serous cystadenocarcinomas in the malignant group ${ }^{11}$. Mature cystic teratoma is the most common germ cell tumour and acconts for $40-50 \%$ of all ovarian neoplasms. Abdominal discomfort was the major symptom presented by malignant epithelial tumours ${ }^{12}$. Malignant germ cell tumours were presented in earlier age group whereas malignant epithelial tumours more prevalent in postmenopausal group. The actuarial 5- year survival rate was more than $95 \%$. It is concluded that for young women who wish to preserve child-beariung capacity, regardless of the stage of tumour, fertility preserving surgery with complete surgical staging followed, if necessary by cisplatin-based combination chemotherapy is an appropriate and definite treatment in the absence of involvement of the contralateral ovary and uterus. For patients in whom child - bearing capacity is not an issue, surgery should include abdominal hysterectomy and salphin go opherectomy with complete staging, followed if necessary by chemotherapy ${ }^{13}$. Of the non neoplastic lesions follicular cysts and corpus luteal cysts were commonest $(80 \%)^{14}$.

\section{References}

1. Amatya S, Gurung G, A Rana Annual Clinicopathologic Analysis of Ovarian Tumours at TUTH.

2. Jamal S, Mamoon N, Mushtaq M, Luqman M, Moghal $\mathrm{S}$. The pattern of gynecological malignancies in 968 cases from Pakistan. Ann Saudi Med 2006;26: 382-4.

3. Khan AA, Lukman M, Jamal N, Mushtaq $S$. Clinicopathological Analysis of Ovarian Tumours. Pak J Pathol 2005; 16(1):28-32.

4. Ovarian Cancer Overview, Incidence and Prevalence of Ov arian cancer.

5. What is Ovarian Cancer? What causes Ovarian cancer? Medical News.com page 1-10.

6. Noel S. Weiss, Joseph L.Lyon, Jonath M. Liff, William M.Vollmer, Janet R.Daling. Incidence 
of ovarian cancer in relation to the use of oral contraceptives. Int. J of Cancer 1981; 28(6):669671.

7. Ovarian Cancer: Prevention, Genetics, CausesNational Cancer Institute.

8. Kikkawa,F NawaA, Ishikawa H, kuzuo K, Suganuma N, Hattori S, Furui K, Kawai M, Arii Y. Diagnosis of Squamous Cell Carcinoma Arising from Mature Cystic Treatoma of the Ovary. American Cancer society 1998; 82(11):2249-55.

9. Amatya A, Rana A, Gurung G. Ovarian tumours in childhood and adolescents- our eight years experiences. NJOG2008;3(1): 39-2.

10. El- Yahia AR, Rahman J, Rahman MS,al-Suleiman SA Ovarian tumours in pregnancy. Aust N Z J Obstet Gynaecol. 1991 Nov;31(4):327-30.
11. Jha $\mathrm{R}$, Karki $\mathrm{S}$. Histological pattern of ovarian tumours and their age distribution. Nepal Medical College Journal. 2008 Jun;10 (2): 81-5.

12. Sah P. Shatrughan, Uprety D, Rani S. Journal of Obstetrics and Gynaecology Research 2004 Aug.; (4):303-308.

13. Piura B, Dgani R, Zalel $Y$, Nemet D, Inbar $Y$ Ilana, Cohen Y, Giezerman. Malignant germ cell tumours of the ovary:A study of 20 cases. J of Surgical Oncology 2006 Jul; 59(3):155-161.

14. Gupta N, Bisht D, Agrawal AK, Sharma VK. Retrospective and Prospective study of ovarian tumours and tumour like lesions. Indian Jour nal Of pathology and microbiology 2007; 503):525-27.

\title{
(D) ith Best $\mathscr{T}$ (Dishes to
}

\author{
Shree Birendra Hospital \\ For the Publication of Vol X Issue I \\ MJSBH
}
Bangalamukhi Trade and Concern provide all kinds of Medicine , $x$-ray \& CT Scan Machine

\section{BANGALAMUKHI TRADE CONCERN}

Pulchowk Lalitpur,

Contact:- 00977-9851046732 